\title{
Assisted Research of some Dynamic Behavior Robot's Parameters
}

\author{
Adrian D. Olaru, Serban A. Olaru, Niculae C. Mihai, and Natalia M. Smidova
}

\begin{abstract}
Optimization in Robotics is one of the most important problem to be solved because for that will be possible to obtain the best results to control the space trajectory, to control the vibration with final goal to obtain the extreme precision and stability. In the paper are shown the research of some dynamic behavior parameters like global dynamic transmissibility $(G D T)$, global dynamic compliance $(G D C)$ and damper's transfer function $(D T F)$. All the assisted research were made by using the virtual LabVIEW data acquisition instrumentation and the acquisition board from National Instruments, USA. The applied method solves one small part of the complex problems of the optimisation in robotics.
\end{abstract}

Index Terms-Assisted research, virtual instrumentation, dynamic behavior parameters, global dynamic compliance, global dynamic transmissibility, damper's transfer function.

\section{INTRODUCTION}

The optimizing of the dynamic behavior in Robotics is one of the most important problem to be solved. Without the assisted research isn't possible to study the dynamic behavior because will be necessary to show the variation of the dynamic parameters vs. frequency, to identify some new dynamic behavior parameters, to construct some Fourier spectrum for him, to assisted study of him and establishing the frequency domain where: the damper is efficiently; the transfer function of the damper is maximum; the transmissibility of the vibration between the robot's base and the end-effecter is decreased; the compliance is minimum to be obtained the maximum of the stiffness.

The assisted research was made by using the proper virtual LabVIEW instrumentation and the acquisition board from National Instruments, USA. The stand used for the research is shown in fig.1, for the assisted dynamic behavior parameters of one didactical arm type robot.

The basic concept of the transmissibility, compliance and damper transfer function can be found in almost every vibration fundamentals manual. The definition of the concept of transmissibility rarely was presented, being widely accepted the following formulation [Tustin 2005] [1]:

'Transmissibility: In steady-state vibration, transmissibility

Manuscript received January 20, 2018; revised March 23, 2018. This work was supported in part by the RUSOS European project and was realized together with the mechatronics companies RomSYS S.A from Romania, Techno Accord from Quebec, Canada and Kosice University of Technology, Slovakia.

A. D. Olaru is with the University Politehnica of Bucharest, Romania, 60042 RO (e-mail: aolaru_51@ymail.com).

S. A. Olaru was with RomSys SA, Bucharest, Romania, (e-mail: serban1978@yahoo.com).

N. C. Mihai is with the TechnoAccord SA, Quebec, Canada (e-mail: mniculae@gmail.ca).

N. M. Smidova is with Kosice University of Technology, Slovakia. is the non-dimensional ratio of response motion / input motion: two displacements, two velocities or two accelerations...". Another more complete formulation of the concept, can be found in [Licker 2003][2]: "Mechanical Transmissibility: A measure of the ability of a system either to amplify or to suppress an input vibration, equal to the ratio of the response amplitude of the system in steady-state forced vibration to the excitation amplitude; the ratio may be in force, displacements, velocities, or accelerations". The reviewed literature use the transmissibility function term to define the functions that correspond to the above definitions. There are some exceptions, like in [Pietrzko 1991][3] paper, who introduced the transmissibility in place of the Frequency Response Function $(F R F)$ term, a special case of a function for an un-damped vibratory system.

Precision and stability of all dynamic systems is one of the more important contradictory problem what must be solved by assisted research. This problem is contradictory because if we try to increase the precision imposed from the application, the stability decrease and will be possible to touch or to be closer to the limit of stability, when the element or system couldn't be controlling more, otherwise if we try to increase the stability, the precision will decrease and the element or system will be very slow and will not be able to respect the minimal limit of the desired promptitude [4]-[11]. The other more important thing in the optimization field of the robots' is the global dynamic compliance $(G D C)$ that influences the robot's behavior. In the paper is shown the assisted method with the proper virtual LabVIEW instruments $(V I)$ for the theoretical and experimental assisted research of one didactical arm type robot with DC motors. The virtual instruments were achieved in the LabVIEW ${ }^{\mathrm{TM}}$ soft 8.2 from National Instruments, USA. By data acquisition of the velocities, accelerations, damper force, excitation force and after generating the Fourier spectrum for them will be possible to choose the optimal frequency field for all dynamic behavior researched parameters [10]-[15]. This method will be possible to be used in the assisted research of the many other mechanical applications where it is necessary to know the dynamic behavior, the vibration spectrum and how the constructive and functional parameters of the DC servo systems and the robot's movements in up or down directions (the equilibrium of the robot's arm) determine the major changes of the spectrum and of the dynamic behavior. Now, in the world, all of the dynamic behavior parameters, or the vibration spectrum are made with some complex apparatus with the expensive cost, not by using the LabVIEW instrumentation. This paper tries to develop one general assisted methodology of some dynamic behavior parameters in the real and frequency domain of the articulated arm type robot. In the paper were solved the following problems: (i)the 
theoretical and the experimental assisted research with data acquisition by using the proper theoretical and experimental LabVIEW VI; (ii)the optimization of the dynamic behavior with the virtual proper $V I$-s, by establishing the frequency field of the maximum of the damper force $(D T F)$, the minimum of the global dynamic compliance $(G D C)$, the minimum of the global dynamic transmissibility in the frequency field $(G D T)$.

The Global Dynamic Compliance $(G D C)$, the Global Dynamic Transmisibility (GDT), the Damper Transfer Function $(D T F)$ [16]-[20] are some of the most important parameters of the dynamic behavior of the industrial robot. In the manufacturing systems is necessary to know the vibration behavior of the maschine where will be put the robot, the Viscose Global Dynamic Damper Coefficient (VGDDC), or the Viscose Global Dynamic Damper Equivalent Coefficient $(V G D D E C)$ of his structure and how the variation of accelerations determines the damped mechanical vibrations of the application, to avoid the resonance frequencies from the Fourier spectrum. The paper shows for the first time one assisted research method with proper virtual LabVIEW ${ }^{\mathrm{TM}}$ instruments for determining the $G D C, G D T, D T F$ of the stationary robots. These virtual apparatus that were designed are generally and they can be used in many others mechanical researches and applications. Now, in the world, the $G D C$, $G D T$ and $D T F$ are not determined for the robots in this maner and for that this paper presents a novelty in the Robotics field [21]-[54].

\section{THE AsSISTED RESEARCH}

\section{A. Stand Used in the Assisted Research}

In all assisted research study cases, the design, modeling and simulation offer some on-line results what can be used to choose some optimal values of the constructive and functional parameters to obtain one required dynamic behavior: without vibration components in the resonance field, without vibration with large amplitudes, one short acceleration time in concordance with the accepted vibration field, minimal stationary errors of the space trajectory of the end-effecter, one bigger Bode frequency to assure one minimum acceleration time, one higher cutting Bode frequency, one higher proper and natural frequencies. In the proper assisted research papers [9]-[11], [15] were shown some results that can be used by the researchers in the robot design activities.

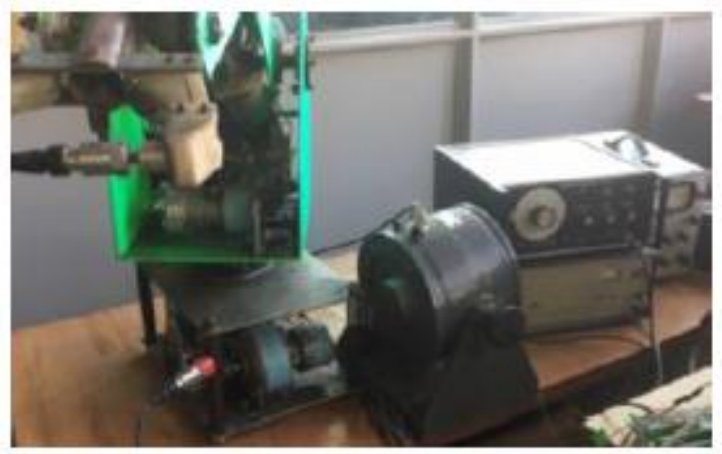

Fig. 1. Research setup of the GDC, GDT, DTF.

The experimental setup contents the followings: - the didactical arm type robot that used for the research;- the exciter systems with the following components: frequency generator to assure the periodical sinusoidal signal with different frequencies and amplitudes; the amplifier to increase the applied electrical tension to the exciter; the electro dynamic exciter that transform the electrical exciter tension in the exciter force with different magnitude and frequencies; - the measure system with the following components: the inductive transducer to determine the damper force; the air damper; the inductive Hottinger bridge to measure the damper force; the tacho to determine by integration the displacement of the robot's arm; the electrical resistance positioned on the excitation electrical wire to measure the tension loss and convert them in to the excitation force; two accelerometers to measure the acceleration on the robot's base and end-effecter; the connector of the acquisition board; the acquisition board from National Instruments, USA; the LabVIEW soft and the acquisition virtual instrument $V I$ for the 5 channels- robot's base acceleration, end-effecter robot's acceleration, excitation force, velocity of the robot's arm and damper force.
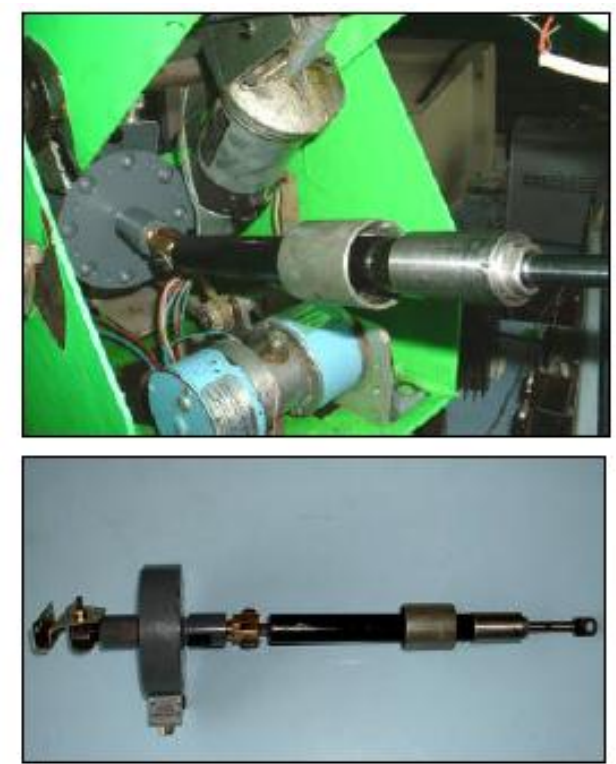

Fig. 2. The part of the setup: a) air damper; b) air damper with inductive traducer.

\section{B. The Research Method}

The assisted method for the research of the GDC, GDT, $D T F$ used the acquisition data from the traducers and used the following mathematical forms:

$$
\begin{aligned}
& G D C=\frac{F F T(x)}{F F T\left(F_{e x}\right)} \\
& G D T=\frac{F F T\left(a_{e n d}\right)}{F F T\left(a_{\text {base }}\right)} \\
& D T F=\frac{F F T\left(F_{d}\right)}{F F T\left(F_{e x}\right)}
\end{aligned}
$$

where: $G D C$ - global dynamic compliance; $F F T(\mathrm{x})-$ fast Fourier transform of the displacement of the robot's arm; $F F T\left(\mathrm{~F}_{\mathrm{ex}}\right)$ - fast Fourier transform of the excitation force on the robot's base; GDT- global dynamic transmissibility; $F F T\left(\mathrm{a}_{\mathrm{end}}\right)$ - fast Fourier transform of the robot's end-effecter acceleration; FFT $\left(\mathrm{a}_{\text {base }}\right)$ - fast Fourier transform of the robot's base acceleration; $D T F$ - dynamic transfer function; $F F T\left(\mathrm{~F}_{\mathrm{d}}\right)$ - 
fast Fourier transform of the damper force; $F F T\left(\mathrm{~F}_{\mathrm{ex}}\right)$ - fast Fourier transform of the excitation force.

For determine the $G D C$, was measured the displacement of the robot's arm and the excitation force on the robot's base, during the variation of the excitation force frequency, between $5-500 \mathrm{~Hz}$. Using the LabVIEW VI will be determine the frequency Fourier spectrum. Will be shown the minimum values of the magnitude of the $G D C$ vs. the frequency field. To determine the minimum values of the $G D C$ vs. excitation frequency is necessary to know how the robot structure change his stiffness vs. frequency, finally to avoid the frequency field what determine the increasing the compliance, increasing the displacement of the end-effecter at the external perturbation forces what could transform the robot's structure in to one un controlling robot.

The variation of the GDT vs. frequency is necessary to know to avoid the frequency field where the GDT increase.

$D T F$ is the dynamic parameter that confirm the frequency field where the damper force is active and it is possible to use them. Where the DTF is minimum vs. frequency it means that the damper is unusual. His effect is decreased and it is not efficient. Finally the needed the frequency field (Optimal Field) must be:

$$
O F \in\{\min (G D C)\} \wedge\{\min (G D T)\} \wedge\{\max (D T F)\}
$$

\section{Proper Virtual LabVIEW Instrumentation}

The front panel of the used LabVIEW VI is shown in Fig.3.

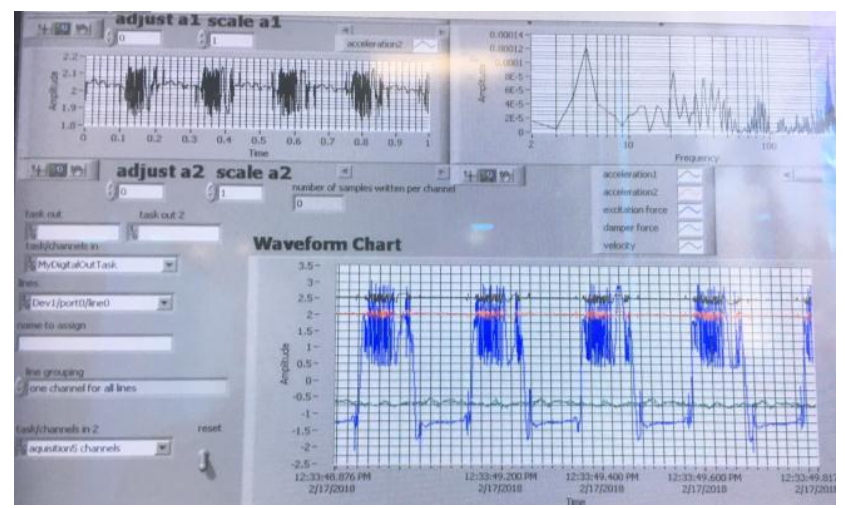

Fig. 3. The front panel of the LabVIEW VI of the aquisition data.

\begin{tabular}{|r|r|}
\hline Frecvența & TDG \\
\hline 5 & $1.00 \mathrm{E}-06$ \\
\hline 6 & $2.50 \mathrm{E}-06$ \\
\hline 7 & $2.50 \mathrm{E}-05$ \\
\hline 8 & $4.00 \mathrm{E}-05$ \\
\hline 9 & $1.00 \mathrm{E}-04$ \\
\hline 10 & $1.50 \mathrm{E}-04$ \\
\hline 20 & $3.50 \mathrm{E}-03$ \\
\hline 30 & $8.00 \mathrm{E}-04$ \\
\hline 40 & $1.00 \mathrm{E}-04$ \\
\hline 50 & $1.00 \mathrm{E}-04$ \\
\hline 60 & $6.00 \mathrm{E}-04$ \\
\hline 70 & $2.00 \mathrm{E}-03$ \\
\hline 80 & $3.00 \mathrm{E}-03$ \\
\hline 90 & $2.00 \mathrm{E}-03$ \\
\hline 100 & $1.50 \mathrm{E}-02$ \\
\hline 200 & $1.80 \mathrm{E}-01$ \\
\hline 300 & 2.4 \\
\hline 400 & $1.50 \mathrm{E}+01$ \\
\hline 500 & 1.2 \\
\hline & \\
\hline
\end{tabular}

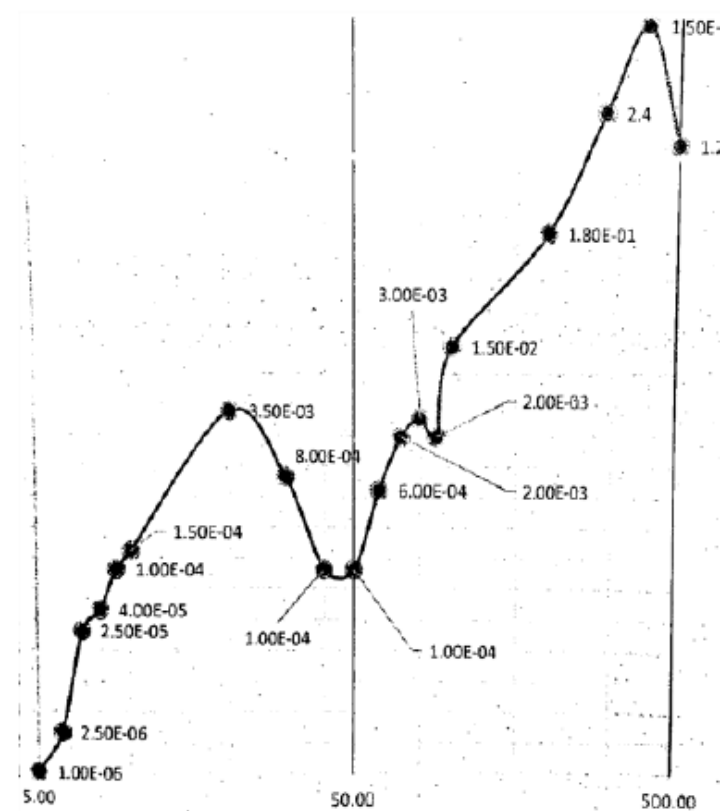

Fig. 4. The GDT vs. frequency.

GDC- global dynamic compliance;

\begin{tabular}{|r|r|r|r|}
\hline Frecventa & Fa[N] & Fex[N] & FT \\
\hline 5 & 1.2 & 0.0013 & 923.0769 \\
\hline 6 & 1.2 & 0.001 & 1200 \\
\hline 7 & 1 & 0.0014 & 714.2857 \\
\hline 8 & 1 & 0.0005 & 2000 \\
\hline 9 & 0.8 & 0.0004 & 2000 \\
\hline 10 & 0.7 & 0.0005 & 1400 \\
\hline 20 & 2 & 0.008 & 250 \\
\hline 30 & 1.8 & 0.007 & 257.1429 \\
\hline 40 & 2.2 & 0.006 & 366.6667 \\
\hline 50 & 1.8 & 0.001 & 1800 \\
\hline 60 & 2.9 & 0.0065 & 446.1538 \\
\hline 70 & 3 & 0.0004 & 7500 \\
\hline 80 & 2.8 & 0.0005 & 5600 \\
\hline 90 & 2.8 & 0.0001 & 28000 \\
\hline 100 & 2 & 0.00001 & 200000 \\
\hline 200 & 2.8 & 0.0001 & 28000 \\
\hline 300 & 2.6 & 0.00008 & 32500 \\
\hline 400 & 3.2 & 0.0001 & 32000 \\
\hline 500 & 2.6 & 0.00008 & 32500 \\
\hline
\end{tabular}

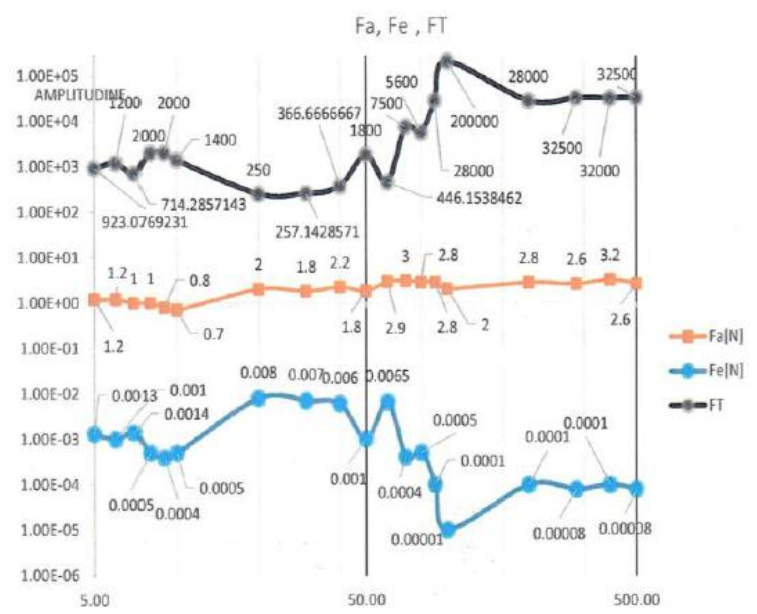

Fig.5 The GDC vs. frequency.

DTF- damper transfer function. 


\begin{tabular}{|r|c|c|c|}
\hline Frecventa & \multicolumn{1}{|l|}{ X } & F & CDG \\
\hline 5 & $4.00 \mathrm{E}-05$ & $6.00 \mathrm{E}-04$ & $6.67 \mathrm{E}-02$ \\
\hline 6 & $5.00 \mathrm{E}-05$ & $6.00 \mathrm{E}-04$ & $8.33 \mathrm{E}-02$ \\
\hline 7 & $3.00 \mathrm{E}-04$ & $1.00 \mathrm{E}-04$ & $3.00 \mathrm{E}+00$ \\
\hline 8 & $1.00 \mathrm{E}-04$ & $2.00 \mathrm{E}-04$ & $5.00 \mathrm{E}-01$ \\
\hline 9 & $2.00 \mathrm{E}-04$ & $1.00 \mathrm{E}-04$ & $2.00 \mathrm{E}+00$ \\
\hline 10 & $2.00 \mathrm{E}-04$ & $3.00 \mathrm{E}-04$ & $6.67 \mathrm{E}-01$ \\
\hline 20 & $2.20 \mathrm{E}-03$ & $3.00 \mathrm{E}-03$ & $7.33 \mathrm{E}-01$ \\
\hline 30 & $1.75 \mathrm{E}-03$ & $3.00 \mathrm{E}-04$ & $5.83 \mathrm{E}+00$ \\
\hline 40 & $1.60 \mathrm{E}-03$ & $1.20 \mathrm{E}-03$ & $1.33 \mathrm{E}+00$ \\
\hline 50 & $6.20 \mathrm{E}-04$ & $4.00 \mathrm{E}-04$ & $1.55 \mathrm{E}+00$ \\
\hline 60 & $1.50 \mathrm{E}-03$ & $6.20 \mathrm{E}-04$ & $2.42 \mathrm{E}+00$ \\
\hline 70 & $2.50 \mathrm{E}-04$ & $1.50 \mathrm{E}-04$ & $1.67 \mathrm{E}+00$ \\
\hline 80 & $7.00 \mathrm{E}-04$ & $1.00 \mathrm{E}-04$ & $7.00 \mathrm{E}+00$ \\
\hline 90 & $1.00 \mathrm{E}-04$ & $8.00 \mathrm{E}-05$ & $1.25 \mathrm{E}+00$ \\
\hline 100 & $5.00 \mathrm{E}-05$ & $6.00 \mathrm{E}-05$ & $8.33 \mathrm{E}-01$ \\
\hline 200 & $1.80 \mathrm{E}-04$ & $5.00 \mathrm{E}-05$ & $3.60 \mathrm{E}+00$ \\
\hline 300 & $3.00 \mathrm{E}-04$ & $5.00 \mathrm{E}-05$ & $6.00 \mathrm{E}+00$ \\
\hline 400 & $1.50 \mathrm{E}-04$ & $5.00 \mathrm{E}-05$ & $3.00 \mathrm{E}+00$ \\
\hline 500 & $2.00 \mathrm{E}-05$ & $7.00 \mathrm{E}-05$ & $2.86 \mathrm{E}-01$ \\
\hline & & & \\
\hline
\end{tabular}

The VI-s contents the following modules: one module with input data contents the name of the acquisition devise, the command line, the output application name and acquisition application name; one module to establishing the scale of the characteristics; one module of the Fourier spectrum characteristics of all dynamic parameters $G D C, G D T$ and DTF.

\section{The Results of the Researched Dynamic Behavior Parameters and Discussion}

This paper tries to develop one general assisted methodology of the dynamic behavior in the real and frequency domain of the articulated arm type didactical robot. In the paper were solved the following problems: the theoretical and the experimental assisted research with data acquisition by using the proper theoretical and experimental LabVIEW VI; the optimization of the dynamic behavior with the virtual proper $V I$-s; the choice of the optimal frequency field when all three dynamic behavior parameters are optimal The actual research in the world does not approach the assisted virtual instrumentation for the optimization of the dynamic behavior parameters that were studied in this research [44]-[54].

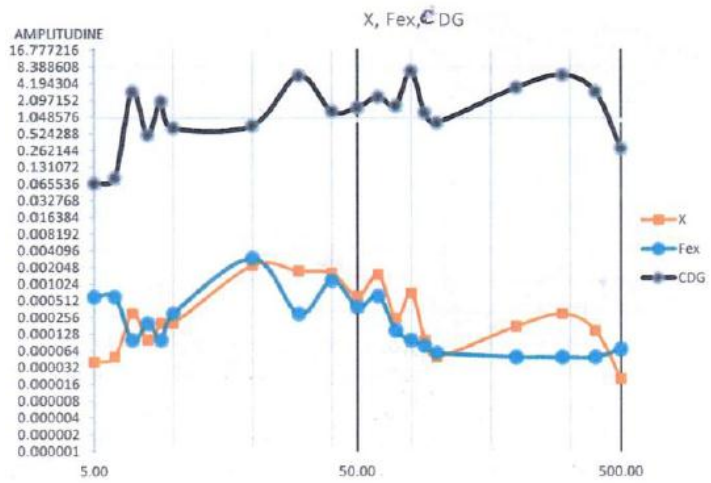

Fig.6. The characteristics of the DTF, damper force and excitation force.

\section{OPTIMIZATION OF THE ROBOT DYNAMIC BEHAVIOR BY USING THE RESULTS}

One way to optimize the dynamic behavior of the is to find the frequency field where all studied parameters are optimal: the $G D T$ is minimum, the $G D C$ is minimum and the $D T F$ is maximum. In this frequency field the effect of the damper and the robot's stiffness will be maximum and the effect of the vibration to the end-effecter will be minimum. After calculate the relation (4) will obtain the following: $\min (G D C) \in[5,6] \mathrm{U}[8,20] \mathrm{U}[40,50] \mathrm{U}[60,70] \mathrm{U}[400,500]$; $\min (G D T) \in[5,10] \mathrm{U}[40,50] ; \quad \max (D T F) \in$ $[8,9] \mathrm{U}\{50\} \mathrm{U}[70,500] ; O \in \min (G D \wedge \min (G D T) \wedge \max (D T F)$;

$$
O F \in[8,9] \cup\{50\} \text {; }
$$

We know that between the working frequency and the acceleration time of the movement is the relation:

$$
t_{a}=\frac{1}{2 v}
$$

To obtain the function objective rel.(5), the field of the acceleration time in this condition, must be:

$$
\mathrm{t}_{\mathrm{a}} \in\{0.01 ; 0.05 ; 0.0625\}
$$

\section{CONCLUSION}

The results shown in the paper, the researched dynamic behavior parameters, the method and the LabVIEWVI-s can be used in many other research in the robotics field.

\section{ACKNOWLEDGMENT}

The authors tanks to University Politehnica of Bucharest, RomSys Company, TechnoAccord Private Company and Kosice University of Technology for technical support of this research.

\section{REFERENCES}

[1] W. Tustin, Equipment Reliability Institute: Vibration and Shock Glossary. [Online]. Available: http://www.vibrationandshock.com

[2] M. D. Licker, Dictionary of Engineering, Second Edition, McGraw-Hill, 2003.

[3] S. Pietrzko, "Comparison of driving point and transmissibility frequency response function of vibratory systems," in Proc. 9th International Modal Analysis Conference, IMAC 9, Florence, Italy, 1991.

[4] A. Olaru, "Virtual LabVIEW instrumentation in the technical research of the robots elements and the systems," Bren Publishing House, 2002, pp.68-75.

[5] A. Olaru, "Dynamic of the industrial robots", vol. 2, Bren Publishing House, 2001, pp. 167-175.

[6] A. Olaru and N. Mihai, "Dynamic of the industrial robots," vol. 1, Bren Publishing House, 1999, pp.106-120.

[7] A. Oprean and A. Olaru, "Theoretical and experimental analyze of position and velocity at articulated arm industrial robot" Proceedings of the Int. Conf. On Solid Mechanics, Romanian Academy, 2001 pp.230-238.

[8] A. Olaru, "Theoretical and experimental research of cinematic and dynamic behavior of industrial robots" in Proc. the $12^{\text {th }}$ International DAAAM Symposium, 2001, pp.333-334.

[9] A. Olaru, "Assisted analyze of the extenics dependent functions in 1D, 2D, 3D and nD dimensions with LabVIEW instrumentation," ICNCT2013, Proceedings, Seul, 2013.

[10] A. Olaru, Dynamic of industrial Robots, Bren Edition 2001, Vol. II, ISBN 973-8143-65-9, Bucharest, 2001.

[11] A. Olaru and N. Mihai, Dynamic of Industrial Robots, Bren Edition 1999, Vol. I, ISBN 973- 9493-35-1, Bucharest, 1999.

[12] D. J. Ewins, Theory and Practice, In Modal Testing; John Wiley \& Sons, Inc.: New York, 1984. 
[13] E. O. Brigham, In The fast Fourier Transform and its Applications; Pretince Hall Inc.: Englewood Cliffs, New Jersey, 1988.

[14] T. Butz and O. Stryk, "Modelling and simulation of rheological devices," Sonderforshungsbereich, Tehnische Universitat Munchen, Universitat Augsburg, Preprint SFB-438-9911, 1999.

[15] S. Olaru, A. Oprean, A. Olaru, "Assisted research of the new bouc-wen rheological damper," in Proc. OPTIROB 2008, (Ed.) Olaru, A. pp.143-152, ISBN 978-973-648-784-2, Predeal, may 2008, Bren, Bucharest, 2008.

[16] J. Angeles, F. Ranjbaran, and R.V. Patel, "On the design of the kinematic structure of seven axes redundant manipulators for maximum conditioning," in Proc. IEEE Int. Conf. Robotics and Automation, pp. 494-499, ISBN 0-8186-2720-4, Nice, France, May1992.

[17] J. Angeles, "Fundamentals of robotic mechanical systems: Theory, methods, and algorithms," 3rd Edition, Springer \& Verlag, ISBN-10: 0387945407, New York, 2006.

[18] M. Hajduk, J .Semjon, M. Vagaš, "Design of the welding fixture for the robotic station for spot weldind based on the modular concept," Acta Mechanica Slovaca, no. 3/2009, vol. 13, pp. 30-35, ISSN 1335-2393.

[19] M. Hajduk, M. Sukop, V. Baláž, J. Semjon, M. Vagaš, 'Improving the performance of manufacturing systems based reconfiguring and computer integration," in Proc. Robtep, Košice, 2006.

[20] D. J. Ewins, Theory and Practice, In Modal Testing; John Wiley \& Sons, Inc.:New York, 1984.

[21] A. Olaru et al., "Optimizing the global dynamic compliance by using the smart damper and LabVIEW instrumentation," Applied Mechanics and Materials, vol. 186, pp. 26-34, 2012

[22] A. Olaru and S. Olaru, "Research of the industrial robots viscose global dynamic damper coefficient with LabVIEW instrumentation," in Proc. CAX'2006, (Ed.) Mikolajczyk T., pp.73- 81, ISBN 978-83-89334-49-7, Bydgoszcz, nov. 2006, Akademia Techniczno-Rolnicza, Bydgoszcz.

[23] M. Tesch, K. Lipkin, I. Brown, R. Hatton, A. Peck, J. Rembisz, and H. Choset, "Parameterized and Scripted Gaits for Modular Snake Robots," Advanced Robotics, vol. 23, no. 9, pp. 1131-1158, Jun. 2009.

[24] D. R. Jones, "A taxonomy of global optimization methods based on response surfaces," Journal of Global Optimization, vol. 21, no. 4, pp. 345-383, 2001

[25] J. L. Cohon, "Multi objective programming and planning," Courier Dover Publications, 2004.

[26] V. Coverstone-Carroll, "Optimal multi-objective low-thrust spacecraft trajectories," Computer Methods in Applied Mechanics and Engineering, vol. 186, no. 2-4, pp. 387-402, Jun. 2000.

[27] J. Knowles, "ParEGO: A hybrid algorithm with on-line landscape approximation for expensive multiobjective optimization problems," IEEE Transactions on Evolutionary Computation, vol. 10, no. 1, pp. 50-66, Feb. 2006.

[28] L. Dixon and G. Szego, "The global optimization problem: an introduction," Towards Global Optimization, vol. 2, pp. 1 - 15, 1978.

[29] A. Zilinskas, "Are view of statistical models for global optimization," Journal of Global Optimization, vol. 2, no. 2, pp. 145-153, Jun. 1992.

[30] Y. P. Papalambros and J. D. Wilde, Principles of Optimal DesignModeling and Computation, Cambridge University Press, 1988.

[31] T. Yoshikawa, "Manipulability of robotic mechanisms," International Journal of Robotic Research, vol. 4, no. 2, pp. 3-9. 1985.

[32] H. Asada, "A geometrical representation of manipulator dynamics and its application to arm design, Transactions of ASME," Journal of Dynamic Systems., Meas. and Control, vol. 105, pp. 131-135. 1983.

[33] T. Graettinger and B. H. Krogh, "The acceleration radius: A global performance measure for robotics manipulators," Journal of Robotics and Automation, vol. 4, no. 1,1988.

[34] A. Bowling, "Analysis of robotic manipulator dynamic performance: Acceleration and force capabilities," PhD-thesis, Stanford University, 1998.

[35] M. Ou and J. Angeles, "Optimum design of manipulators under dynamic isotropy conditions," in Proc. IEEE International Conference on Robotics and Automation, vol. 1, pp. 470-475, 1993.

[36] W. A. Kahn and J. Angeles, "The kinetostatic optimization of robotic manipulators: The inverse and the direct problems," Transactions of the ASME Journal of Mechanical Design, vol. 128, no. 1, pp. 168-178, 2006.

[37] J. K.Salisbury and J. J. Craig, "Articulated hands: Force control and kinematic issues," International Journal of Robotics Research, vol. 1, no. 1 , pp. 4-17, 1982.

[38] S. Kirkpatrick, C. D. Gelatt, and M. P. Vecchi, "Optimization by simulated annealing," Science, vol. 220, pp. 671-680, 1983.

[39] L. Ciupitu, "Complex analytic curves for Industrial robot trajectories," in Proc. the 3-rd Asian Conference on Robotics and Its Application, Tokyo, Japan, pp. 211-218.
[40] L. Ciupitu and I. Simionescu, "Optimal location of robot base with respect to the application positions," in Proc. the 2-nd International Conference on "Optimization of the Robots and Manipulators OPTIROB 2007, Predeal, Romania, 27-29 May 2006,

[41] L. Ciupitu, S.Brotac and S. Chivescu, "Optimum position of an industrialrobot used in forge applications," in Proc. the 4-th International Conference on "Optimization of the Robots and Manipulators" OPTIROB 2009, ISBN 2066-3854, Editors: Olaru, A., Ciupitu, L. and Olaru, S., Constanta, Mamaia, Romania, May 28-th31-st, 2009, pp. 43-47.

[42] J. Denavit and R. S. Hartenberg, "A kinematic notation for lower-Pair mechanisms based on matrices," Trans. of ASME, Journal of Applied Mechanics, 23: 215-221.

[43] J. T. Feddema, "Kinematically optimal placement for minimum time coordinated motion, robotics and automation," vol. 4, 1996, pp. 3395-3400.

[44] F. Kovacs and G. Cojocaru, "Manipulatoare, roboți si aplicaţiile lor industriale," Editura Facla, Timişoara, 1982.

[45] I. Simionescu, V. Moise and L. Ciupitu, "Sinteza funcţiilor de transmitere ale mecanismelor," Journal of Romanian Academy "Studii și Cercetări de mecanică aplicată," no. 5-6, 1996, pp. 409-426.

[46] L. Tian and C. Collins, "Optimal placement of a two-link planar manipulator using a genetic algorithm," Robotica Journal, Cambridge University Press, vol. 23, pp. 169-176, 2005.

[47] A. Olaru, S. Olaru, and N. Mihai, "Proper assisted research method solving of the robots inverse kinematics problem," Applied Mechanics and Materials, vol. 555, 2014, pp. 135-147.

[48] A. Olaru, S. Olaru, and L. Ciupitu, "Assisted research of the neural network by back propagation algorithm," in Proc. OPTIROB 2010 International Conference, Calimanesti, Romania, The Reserch Publishing Services Singapore Book, 2010, pp. 194-200.

[49] A. Olaru, S. Olaru, and N. Mihai, "Proper assisted research method solving of the robots inverse kinematics problem," Applied Mechanics and Materials, vol. 555, 2014, pp. 135-147.

[50] A. Olaru, S. Olaru, and L. Ciupitu, "Assisted research of the neural network by back propagation algorithm," in Proc. OPTIROB 2010 International Conference, Calimanesti, Romania, May 28-th-30-th, 2010.

[51] S. A. Billings and J. J. C. Peyton, "Mapping non-linear integro-differential equations into the frequency domain," International Journal of Control, vol. 52, no. 4, pp. 863-879.

[52] A. Carrella, M. J. Brennan, T. P. Waters, and V. Lopes, "Force and displacement transmissibility of a nonlinear isolator with high-static-low-dynamic-stiffness," International Journal of Mechanical Sciences, vol. 55, no. 1, pp. 22-29, 2012.

[53] S. Chakraverty and D. Behera, "Dynamic responses of fractionally damped mechanical system using homotopy perturbation method," Alexandria Engineering Journal, 52(2013), 557-562, 2013.

[54] K. Diethelm and A. D. Freed, "The frac PECE subroutine for the numerical solution of differential equations of fractional order," Forschung und wissenschaftliches Rechnen, 1999, pp. 57-71, 1998.

[55] G. J. Efstathiades and C. J. H. Williams, "Vibration isolation using non-linear springs," International Journal of Mechanical Sciences, vol. 9, pp. 27-44, 1967.

[56] B. Fang, S. Li, and W. Huang, " Performance analysis for a new whole-spacecraft isolation using viscoelastic damping material," International Society for Optics and Photonics, 2011.

[57] R. Genesio and A. Tesi, "Harmonic balance methods for the analysis of chaotic dynamics in nonlinear systems," Automatica, vol. 28, no. 3, pp. 531-548, 1992.

[58] F. Guo, C. B. Du, and R. P. Li, "Relaxation constitutive model for magnetorheological elastomers based on fractional derivative," Nanjing: Hohai University, 2012.

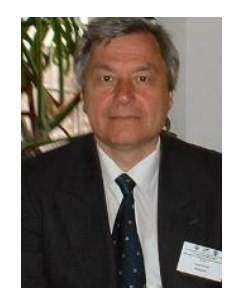

Adrian Olaru finishes the University Politehnica of Bucharest, the Faculty of Machine-Tools, Machine and Manufacturing Systems Department. Now, from 1998, he is a university full professor, and he teach the following courses: Industrial Robots Dynamics Behavior, LabVIEW application in modeling and simulation of the dynamic behavior of robots and Personal and social robots. I am a doctor from 1989. In the last ten years he have been leading the following research projects: computer aided research and design for the hydraulic amplifiers of pneumatic and hydraulic screwdrivers; computer aided research over the dynamic behavior of the forging manipulator orientation modulus; computer aided research over dynamic behavior of the charging manipulators tipping modulus; computer aided research over dynamic behavior of the charging manipulators translation modulus; experimental 
validation for mathematical models of hydraulic elements and servo system; methodological guide for dimensioning and optimizing electrohydraulic elements; design of the mobile robots; assisted research of the magneto rheological dampers; assisted research of the intelligent dampers; assisted research of the neural networks; optimizing of the robots dynamic behavior by using the Fourier proper analyzer; optimizing the dynamic compliance and global transmissibility by using the assisted research and proper LabVIEW instrumentation; optimize the dynamic behavior and the space trajectory by using the proper neural network.

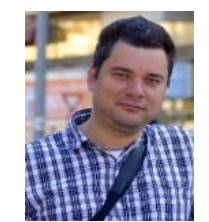

Serban Olaru finished the University Politehnica of Bucharest, Faculty of Machines and Manufacturing Systems, Romania. From 2008 he become the $\mathrm{Ph} . D$.Eng.in the field of mechatronics. Now, he works in RomSYS private company, from Bucharest, Romania, in the department of mechatronics. He write mote than 50 research papers in the fields of intelligent damper systems, mechatronic systems, simulation and modeling with LabVIEW instrumentation.
Niculae Mihai finished the University Politehnica of Bucharest, Faculty of Machines and Manufacturing Systems, Romania.

From 2006 he become Ph.D.Eng. in the field of robotics. Now, he is the manager of the private company in mechatronics systems, Technoaccord, Quebec, Canada.

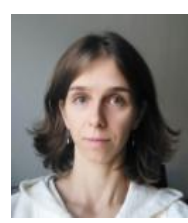

Natalia Smidova was graduated from Faculty of Mathematics and Physics, Charles University in Prague in 2005, works at Department of Physics, Faculty of Electrical Engineering and Informatics, Technical University of Kosice. Oriented on investigation of material properties by spectroscopic (nuclear magnetic resonance (NMR) and Raman) methods; She is interested in polymers an polymer nanocomposites made from renewable resources. 